\title{
How I prescribe continuous renal replacement therapy
}

\author{
Emily J. See $1,2,3$ and Rinaldo Bellomo 1,3,4,**
}

\section{Introduction}

Continuous renal replacement therapy (CRRT) delivers gradual clearance of solutes, fluid balance control, and haemodynamic stability. CRRT does not appear to increase survival compared to intermittent renal replacement therapy (IRRT), but may affect renal recovery $[1,2]$. Here, we describe how we prescribe CRRT (Fig. 1).

\section{Timing of initiation}

Early CRRT initiation may not improve outcomes, and the definition of "early" varies between studies [3-5]. Therefore, clinical judgement guides CRRT initiation. We aim to prevent or rapidly treat life-threatening derangements in fluid status, electrolytes, and/or acid-base balance and to meet metabolic and fluid needs that residual kidney function cannot address.

\section{Catheter selection}

Catheters should be of sufficient gauge (13 Fr or 13.5 Fr) to deliver the desired blood flow rate without high negative pressures. The insertion site depends on clinical judgement. Catheter function is best with the right internal jugular vein, followed by femoral vein, and left internal jugular vein [6]. We avoid any other lines in the same vessel and the subclavian vein due to the risk of thrombosis or stenosis. Targeting soft tip position in the right atrium or in the proximal inferior vena cava helps maximise circuit life [7]. Triple lumen catheters (13 Fr) facilitate calcium administration during citrate anticoagulation. However, blood for ionised calcium

*Correspondence: rinaldo.bellomo@austin.org.au

${ }^{1}$ Department of Intensive Care, Austin Hospital, 145 Studley Road, Heidelberg, VIC, Australia

Full list of author information is available at the end of the article measurements should come from the arterial line. Avoiding femoral access in obese patients may decrease catheter-related bloodstream infections [8].

\section{Anticoagulation}

The risks of clotting and bleeding must be carefully considered. Regional (e.g. citrate-calcium or heparinprotamine) or systemic anticoagulation approaches (e.g. unfractionated heparin, low molecular weight heparin) are available. Regional citrate anticoagulation reduces the risk of circuit loss, filter failure, bleeding, and heparin-induced thrombocytopaenia [9]. Accordingly, we prescribe regional citrate anticoagulation. We avoid citrate in patients with severe liver failure or a serum lactate $>4 \mathrm{mmol} / \mathrm{L}$ due to the risk of citrate intolerance. In acute liver failure, we typically perform CRRT without anticoagulation.

\section{CRRT modality}

There are three key equivalent CRRT modalities (Fig. 1): Continuous venovenous haemofiltration $(\mathrm{CVVH})$; continuous venovenous haemodialysis (CVVHD); and continuous venovenous haemodiafiltration (CVVHDF) [10]. Accordingly, modality selection is based on local expertise. We preferentially prescribe CVVHDF because it is the most well studied and because diffusion may prolong circuit life [11, 12].

\section{CRRT dose}

CRRT dose is essentially quantified by the effluent flow rate and there is no survival benefit from a dose $>20$ to $25 \mathrm{~mL} / \mathrm{kg} / \mathrm{h} \mathrm{[12]}$. We prescribe an effluent flow rate of $25 \mathrm{~mL} / \mathrm{kg} / \mathrm{h}$ to achieve a delivered dose of at least $20 \mathrm{~mL} / \mathrm{kg} / \mathrm{h}$. Patients with severe metabolic derangements may benefit from higher CRRT dosage [13]. In original author(s) and the source, provide a link to the Creative Commons licence, and indicate if changes were made. The images or other third party material in this article are included in the article's Creative Commons licence, unless indicated otherwise in a credit line to the material. If material is not included in the article's Creative Commons licence and your intended use is not permitted by statutory regulation or exceeds the permitted use, you will need to obtain permission directly from the copyright holder. To view a copy of this licence, visit http://creativecommons.org/licenses/by/4.0/. The Creative Commons Public Domain Dedication waiver (http://creativeco mmons.org/publicdomain/zero/1.0/) applies to the data made available in this article, unless otherwise stated in a credit line to the data. 


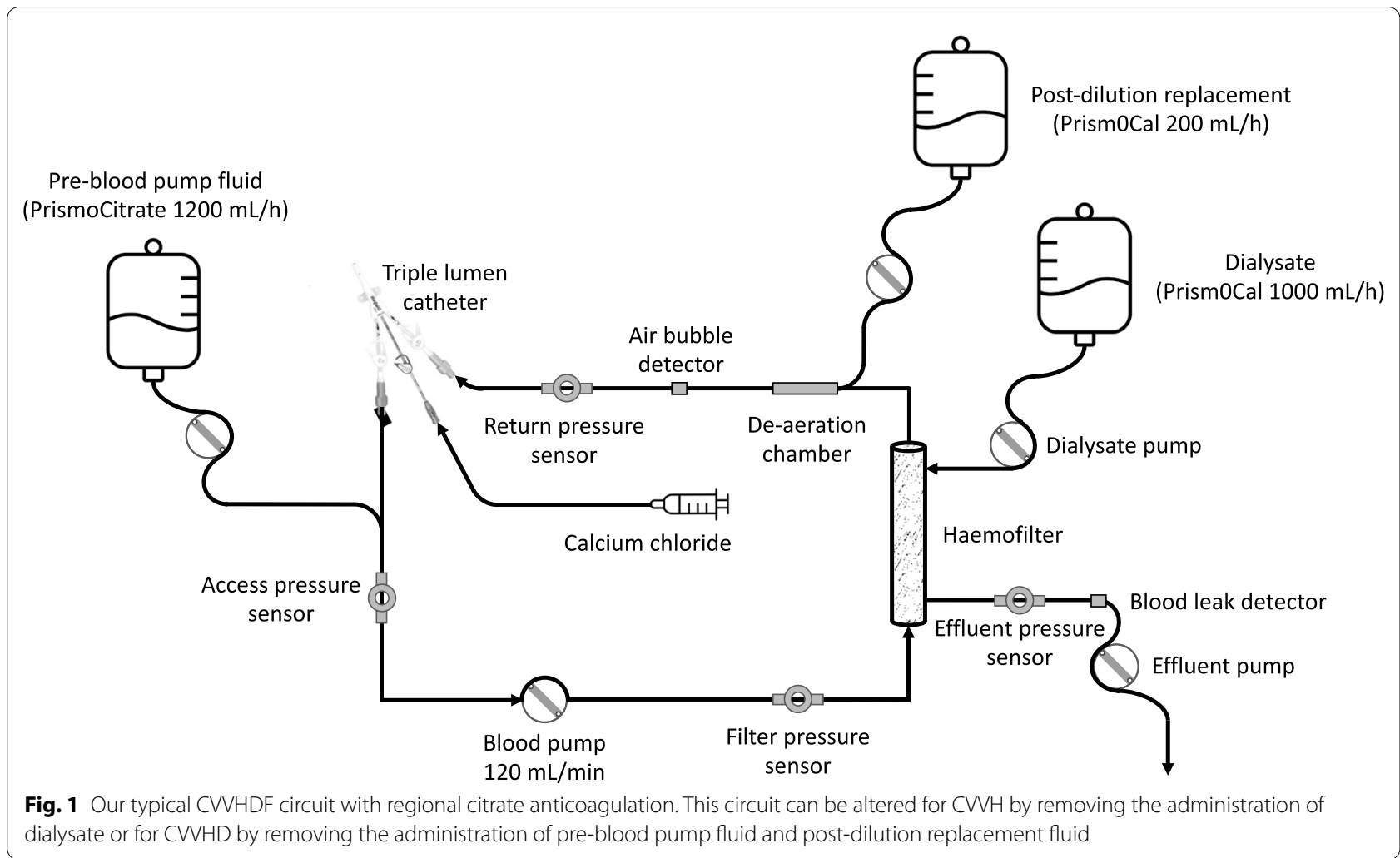

patients with hyperammonaemia $(>100 \mu \mathrm{mol} / \mathrm{L})$, we prescribe $50 \mathrm{~mL} / \mathrm{kg} / \mathrm{h}$ of effluent flow rate to target levels $<100 \mu \mathrm{mol} / \mathrm{L}$. We prescribe a similar intensity CRRT for severe hyperkalaemia.

\section{Blood flow rate}

Blood flow rate prescription varies with modality. For CVVHD, the blood flow rate should be at least twice the dialysate flow rate to maximise the plasma to dialysate concentration gradient. For CVVH, blood flow rate should be titrated to prevent a filtration fraction (plasma water removal to plasma flow ratio) $>25 \%$. Pre-filter replacement fluid administration requires adjustment to this calculation. We reach our target blood flow rate in a stepwise manner starting at $25 \mathrm{~mL} / \mathrm{min}$ and increasing slowly (over 10-15 min). Once established, typical blood flow rates $(150-250 \mathrm{~mL} / \mathrm{min})$ do not affect haemodynamics. For citrate CVVHDF, we prescribe a lower blood flow rate of $120 \mathrm{~mL} / \mathrm{min}$ because higher rates necessitate a higher dose of citrate, which increases the risk of citrate toxicity. We do not change blood flow rate according to pre vs. post filter replacement fluid administration, despite differences in solute clearance efficiency.

\section{CRRT solutions}

Bicarbonate-buffered solutions are preferred over lactate-buffered solutions to prevent iatrogenic hyperlactataemia. Phosphate-containing solutions are available. Although effective at preventing hypophosphataemia, they increase the risk of hypocalcaemia and metabolic acidosis [14]. For patients receiving regional citrate anticoagulation, we use commercially available pre-blood pump fluid containing citrate as well as calcium-free dialysate and post-dilution replacement fluid to preserve the anticoagulant effect of citrate. We administer the majority of replacement fluid pre-filter to deliver the prescribed dose of citrate into the circuit. With citrate, we use lower bicarbonate replacement fluids $(22 \mathrm{mEq} / \mathrm{L})$ with either 0 or $4 \mathrm{mmol} / \mathrm{L}$ of potassium, depending on serum potassium levels.

\section{Patient fluid removal}

The difference between ultrafiltration and replacement/ dialysate volumes determines fluid removal. The speed of fluid removal is referred to as the net ultrafiltration (NUF) rate. A high NUF rate in CRRT may be harmful [12], although optimal values are not yet established. Because fluid overload is common and undesirable, we regularly reassess fluid status and adjust NUF rate accordingly. We avoid very high NUF rates $(>2 \mathrm{~mL} / \mathrm{kg} / \mathrm{h})$, 
unless aggressive fluid removal is indicated by life-threatening fluid overload.

\section{Monitoring therapy}

We monitor electrolytes every 6-8 h. We measure ionised calcium, total calcium and plasma bicarbonate 4-6 hourly in patients receiving regional citrate anticoagulation. In keeping with Acute Dialysis Quality Initiative (ADQI) recommendations, we audit CRRT safety and quality by monitoring circuit life, small-solute clearance, delivered dose, catheter dysfunction, catheter infection, and mortality [15].

\section{When to stop}

The decision to discontinue CRRT is based on clinical judgement. However, higher urine output, higher creatinine clearance, and lower serum creatinine can predict successful CRRT cessation [5]. A trial of CRRT cessation is appropriate when spontaneous urine output is $>500 \mathrm{~mL} /$ day and endogenous creatinine clearance is $>15 \mathrm{~mL} / \mathrm{min}$. We delay exposure to IRRT until at least $24 \mathrm{~h}$ after cessation of vasopressor drugs.

\section{Conclusions}

We prefer CVVHDF with regional citrate anticoagulation via a triple lumen catheter inserted into the right internal jugular vein or the right femoral vein. Timing of initiation and cessation of CRRT is based on clinical judgement. We prescribe a blood flow rate of $120 \mathrm{~mL} / \mathrm{min}$ and an effluent flow rate of $25 \mathrm{~mL} / \mathrm{kg} / \mathrm{h}$ with citrate anticoagulation. We avoid aggressive NUF unless clinically indicated. We adjust effluent flow rate for specific patients to target ammonia clearance. We monitor the safety and quality of CRRT and advocate for the use of protocolised care. Although intensivists prescribe CRRT in our unit, we acknowledge that collaborative and multidisciplinary prescription is common worldwide.

\section{Acknowledgements}

Not applicable.

\section{Authors' contributions}

ES and RB contributed equally to the preparation of this manuscript. Both authors read and approved the final manuscript.

\section{Funding}

Not applicable.

\section{Availability of data and materials Not applicable.}

Ethics approval and consent to participate Not applicable.

\section{Consent for publication}

Not applicable.
Competing interests

The authors declare they have no competing interests relevant to this editorial.

\section{Author details}

${ }^{1}$ Department of Intensive Care, Austin Hospital, 145 Studley Road, Heidelberg , VIC, Australia. ${ }^{2}$ Department of Nephrology, The Royal Melbourne Hospital, Parkville, Australia. ${ }^{3}$ Centre for Integrated Critical Care, University of Melbourne, Melbourne, Australia. ${ }^{4}$ Department of Intensive Care, The Royal Melbourne Hospital, Parkville, Australia. ${ }^{5}$ Data Analytics Research and Evaluation, The University of Melbourne and Austin Hospital, Melbourne, Australia.

Received: 3 November 2020 Accepted: 18 December 2020

Published online: 02 January 2021

\section{References}

1. Rabindranath KS, Adams J, MacLeod AM, Muirhead N. Intermittent versus continuous renal replacement therapy for acute renal failure in adults. Cochrane Database Syst Rev. 2007;3:CD003773.

2. Bell M, Granath F, Schön S, Ekbom A, Martling C-R. Continuous renal replacement therapy is associated with less chronic renal failure than intermittent haemodialysis after acute renal failure. Intensive Care Med. 2007;33:773-80.

3. Bagshaw SM, Wald R, Adhikari NKJ, Bellomo R, da Costa BR, Dreyfuss D, et al. Timing of initiation of renal-replacement therapy in acute kidney injury. N Engl J Med. 2020;383:240-51.

4. Gaudry S, Hajage D, Schortgen F, Martin-Lefevre L, Pons B, Boulet E, et al. Initiation strategies for renal-replacement therapy in the intensive care unit. N Engl J Med. 2016;375:122-33.

5. Zarbock A, Kellum JA, Schmidt C, Van Aken H, Wempe C, Pavenstädt H, et al. Effect of early vs delayed initiation of renal replacement therapy on mortality in critically ill patients with acute kidney injury: the ELAIN Randomized Clinical Trial. JAMA. 2016;315:2190-9.

6. Parienti J-J, Mégarbane B, Fischer M-O, Lautrette A, Gazui N, Marin N, et al. Catheter dysfunction and dialysis performance according to vascular access among 736 critically ill adults requiring renal replacement therapy: a randomized controlled study. Crit Care Med. 2010;38:1118-25.

7. Morgan D, Ho K, Murray C, Davies H, Louw J. A randomized trial of catheters of different lengths to achieve right atrium versus superior vena cava placement for continuous renal replacement therapy. Am J Kidney Dis. 2012;60:272-9.

8. Parienti J-J, Thirion M, Mégarbane B, Souweine B, Ouchikhe A, Polito A, et al. Femoral vs jugular venous catheterization and risk of nosocomial events in adults requiring acute renal replacement therapy. JAMA. 2008;299:2413.

9. Bai M, Zhou M, He L, Ma F, LiY, Yu Y, et al. Citrate versus heparin anticoagulation for continuous renal replacement therapy: an updated meta-analysis of RCTs. Intensive Care Med. 2015;41:2098-110.

10. Friedrich JO, Wald R, Bagshaw SM, Burns KEA, Adhikari NKJ. Hemofiltration compared to hemodialysis for acute kidney injury: systematic review and meta-analysis. Crit Care. 2012;16:R146.

11. Califano AM, Bitker L, Baldwin I, Fealy N, Bellomo R. Circuit survival during continuous venovenous hemodialysis versus continuous venovenous hemofiltration. Blood Purif. 2020;49:281-8.

12. Bellomo R, Cass A, Cole L, Finfer S, Gallagher M, Lo S, et al. Intensity of continuous renal-replacement therapy in critically ill patients. N Engl J Med. 2009;361:1627-38.

13. Warrillow S, Fisher C, Bellomo R. Correction and control of hyperammonemia in acute liver failure. Crit Care Med. 2020;48:218-24.

14. Chua H-R, Baldwin I, Ho L, Collins A, Allsep H, Bellomo R. Biochemical effects of phosphate-containing replacement fluid for continuous venovenous hemofiltration. Blood Purif. 2012;34:306-12.

15. Rewa OG, Tolwani A, Mottes T, Juncos LA, Ronco C, Kashani K, et al. Quality of care and safety measures of acute renal replacement therapy: workgroup statements from the 22nd acute disease quality initiative (ADQI) consensus conference. J Crit Care. 2019;54:52-7.

\section{Publisher's Note}

Springer Nature remains neutral with regard to jurisdictional claims in published maps and institutional affiliations. 